NASA Technical Memorandum 107094

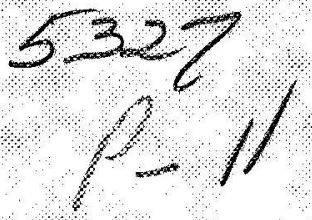

\title{
Robotic Planetary Science Missions Enabled With Small NTR Engine/ Stage Technologies
}

Stanley K. Borowski

Lewis Research Center

Cleveland, Ohio

Prepared for the

12th Symposium on Space Nuclear Power and Propulsion cosponsored by BMDO, NASA, DOE, and USAF

Albuquerque, New Mexico, January 8-12, 1995



National Aeronautics and Space Administration
(NASA-TM-107094) ROBOTIC PLANETARY SCIENCE MISSIONS ENABLEO WITH SMALL NTR ENGINE/STAGE TECHNOLOGIES (NASA. Lewis Research Center)

$11 \mathrm{p}$
N96-12576

Unclas 


\title{
ROBOTIC PLANETARY SCIENCE MISSIONS ENABLED \\ WITH SMALL NTR ENGINE/STAGE TECHNOLOGIES
}

\author{
Stanley K. Borowski \\ NASA Lewis Research Center \\ 21000 Brookpark Road \\ Cleveland, $\mathrm{OH} 44135$ \\ (216) $977-7091$
}

\begin{abstract}
The high specific impulse (Isp) and engine thrust-to-weight ratio of liquid hydrogen $\left(\mathrm{LH}_{2}\right)$-cooled nuclear thermal rocket (NTR) engines makes them ideal for upper stage applications to difficult robotic planetary science missions. A small 15 thousand pound force (klbf) NTR engine using a uranium-zirconium-niobium "ternary carbide" fuel (Isp $\sim 960$ seconds at $\sim 3025 \mathrm{~K}$ ) developed in the Commonwealth of Independent States (CIS) is examined and its use on an expendable injection stage is shown to provide major increases in payload delivered to the outer planets (Saturn, Uranus, Neptune and Pluto). Using a single "Titan IV-class" launch vehicle, with a lift capability to low Earth orbit (LEO) of -20 metric tons ( $t$ ), an expendable NTR upper stage can inject two Pluto "Fast Flyby" spacecraft (PFF/SC) plus support equipment--combined mass of $\sim 508 \mathrm{~kg}$--on high energy, "6.5-9.2 year" direct trajectory missions to Pluto. A conventional chemical propulsion mission would use a liquid oxygen (LOX)/LH "Centaur" upper stage and two solid rocket "kick motors" to inject a single PFF/SC on the same Titan IV launch vehicle. For follow on Pluto missions, the NTR injection stage would utilize a Jupiter "gravity assist" (JGA) maneuver to launch a LOX/liquid methane $\left(\mathrm{CH}_{4}\right)$ capture stage (Isp 375 seconds) and a Pluto "orbiter" spacecraft weighing between $\sim 167-312 \mathrm{~kg}$. With chemical propulsion, a Pluto orbiter mission is not a viable option because of inadequate delivered mass. Using a "standardized" NTR injection stage and the same single Titan IV launch scenario, "direct flight" (no gravity assist) orbiter missions to Saturn, Uranus and Neptune are also enabled with transit times of 2.3,6.6, and 12.6 years, respectively. Injected mass includes a storable, nitrogen tetroxide/monomethyl hydrazine $\left(\mathrm{N}_{2} \mathrm{O} / \mathrm{MMM}\right.$ ) capture stage (Isp 330 seconds) and orbiter payloads 340 to $820 \%$ larger than that achievable using a LOX/LH ${ }_{2}$-fueled injection stage. The paper discusses NTR technology and mission characteristics, shows NTR stage and payload accommodations within the $26.2 \mathrm{~m}$ long Titan IV payload fairing, and discusses NTR stage performance as a function of assumed cryogenic tank technology.
\end{abstract}

\section{INTRODUCTION}

The NTR has been identified in both the "90-Day Study Report" (NASA 1989) and the "Synthesis Group Report" (Synthesis Group 1991) as a critical technology enabling reduced trip time/minimum initial mass in LEO (IMLEO) missions to Mars. The benefits of NTR propulsion for human lunar exploration missions was also documented by NASA Lewis Research Center (Borowski 1991), and an integrated Moon/Mars exploration strategy was proposed (Borowski et al. 1992 and 1993) to reduce space transportation system (STS) development time and cost. In the integrated approach, a "modular" NTR-based STS would be developed which used "standardized" engine and stage components in a "building block" fashion to configure a wide variety of single and multi-engine lunar and Mars vehicles. Clusters of two to four 15 to $25 \mathrm{klbf}$ NTR engines were shown to be sufficient for most of the lunar and "multi-perigee burn" Mars mission scenarios then under consideration by NASA.

In this paper, the benefits of using a single engine, $15 \mathrm{klbf}$ NTR-powered injection stage and Titan IV launch vehicle combination to improve "robotic" science missions to the outer planets (Saturn, Uranus, Neptune and Pluto) is examined. An "expendable mission mode" is baselined here with the NTR upper stage providing primary propulsion for payload injection only. The expendable scenario: (1) reduces engine burn time requirements; (2) eliminates the need for reactor restart and cooldown propellant; (3) allows higher fuel operating temperatures when necessary; and (4) reduces stage thermal protection system (TPS) complexity because long term $\mathrm{LH}_{2}$ propellant storage is no longer a requirement. The ground facilities for testing a $15 \mathrm{klbf}$ NTR with closed effluent treatment system are also expected to be developed more quickly and at lower cost ( $\$ 200$ million) due to the reduced engine size, burn duration and effluent throughput (Buden et al. 1993). 


\section{US/CIS NTR ENGINE CONCEPT/OPERATING CHARACTERISTICS}

The NTR functions by raising low molecular weight hydrogen propellant to high pressure in a turbopump assembly, passing it through a high power reactor where it is heated to high temperature, and then exhausting it through a nozzle at high velocity (twice that of conventional $\mathrm{LOX} / \mathrm{LH}_{2}$-fueled chemical rockets) to generate thrust. Between 1955 and 1973, the United States' Rover/NERVA (Nuclear Engine for Rocket Vehicle Application) nuclear rocket programs conducted numerous reactor and integrated engine system tests which demonstrated the operational characteristics required for robotic, as well as, human exploration missions. The majority of experimental tests were performed using a "graphite" fuel consisting of pyrocarbon coated uranium carbide fuel particles dispersed in a graphite substrate, and operated at hydrogen exhaust temperatures as high as $2550 \mathrm{~K}$ (Koenig 1986).

Four years after NERVA program initiation, a NTR technology program was started in the former Soviet Union known today as the Commonwealth of Independent States (CIS). The CIS has conducted extensive nuclear and non-nuclear tests, including fuel element and reactor tests at the Semipalatinsk facility in Kazakhstan (Clark et al. 1993). Although integrated engine system tests were not conducted, a high performance ternary carbide fuel element (with maximum temperature capability of $\sim 3200 \mathrm{~K}$ ) was developed and a hydrogen exhaust temperature ( $\mathrm{Tex}$ ) of $\sim 3100 \mathrm{~K}$ for over one hour was demonstrated (Clark et al. 1993) in reactor tests. By contrast, the NRX-A6 NERVA developmental reactor operated at $\sim 2350 \mathrm{~K}$ during its one hour endurance burn.

A joint US/CIS industry team of Aerojet, Energopool and Babcock and Wilcox developed a CIS NTR engine design (Culver et al. 1993) under NASA funding which utilizes a heterogeneous reactor core design with hydrogencooled zirconium hydride moderator and ternary carbide fuel materials. The CIS fuel assembly is an axial flow design containing a series of stacked $47 \mathrm{~mm}$ diameter bundles of thin $(-1 \mathrm{~mm})$ "twisted ribbon" fuel elements $\sim 2 \mathrm{~mm}$ in width by $100 \mathrm{~mm}$ in length. The "fueled length" and power output from each assembly is determined by specifying the engine thrust level and hydrogen exhaust temperature (or desired Isp). For a $15 \mathrm{klbf}$ engine, 34 fuel assemblies (with 6 fuel bundles each) are used to generate the required $340 \mathrm{MWt}$ of reactor power at an Isp of -960 seconds.

The US/CIS NTR engine (NTRE) design utilizes a recuperated topping cycle (Culver et al. 1993) with a combination recuperator/gamma radiation shield, located atop the engine to provide the necessary turbine drive power. The $15 \mathrm{klbf}$ CIS engine baselined in this study has a chamber pressure of 2000 psia, a nozzle area ratio of 300 to 1 , and a $110 \%$ bell length nozzle. With today's demonstrated CIS fuel technology, a steady state vacuum Isp of $\sim 960$ seconds should be maintainable for $\sim 1$ hour at $T_{e x} \sim 3025 \mathrm{~K}$. The engine thrust-to-weight ratio, total length and nozzle exit diameter for the $15 \mathrm{klbf}$ US/CIS NTRE are $\sim 3.0,4.3 \mathrm{~m}$ and $1.0 \mathrm{~m}$, respectively.

\section{OUTER PLANET MISSION APPLICATIONS}

\section{Pluto Fast Flyby (PFF) Mission}

Considerable interest presently exists at NASA and the Jet Propulsion Laboratory (JPL) in a flyby mission of Pluto and its large moon Charon (Asker 1993). In addition to Pluto being the outermost and only planet in our solar system not yet visited by robotic spacecraft, it also appears to be the only world with an atmosphere that forms and decays during its orbital cycle. Planetary scientists predict that Pluto's thin, largely methane atmosphere (discovered in 1988) will condense out on the planet's surface in the 2015 to 2020 timeframe as Pluto journeys outward from the Sun. Pluto's last perihelion was in 1989 and with a 248 year period of revolution its atmosphere is not expected to reappear until approximately the year 2237.

Initial JPL plans for a PFF mission envision two lightweight spacecraft (each $\sim 164 \mathrm{~kg}$ ) launched separately on "fast" direct trajectories to the Pluto-Charon system. Each spacecraft would require a Titan IV/Centaur launch vehicle and utilize two solid-fuel "kick motors" (Star 48B and Star 27) to achieve the high injection $\Delta \mathrm{V}$ of $\sim 12 \mathrm{~km} / \mathrm{s}$ required for an 8 year trip time. With a 2001 launch date, Pluto flyby would occur in $2009-2010$. The two spacecraft are scheduled to encounter Pluto $~ 3.2$ days apart, albeit at very high speed, and with Pluto's rotational period of 6.4 days, a "two spacecraft strategy" permits mapping of the entire planet. Initial costs for the PFF mission were estimated to be $-\$ 1.35$ billion which included $\$ 400$ million for the spacecraft pair, $\$ 800$ million for the two launch vehicles and $\$ 150$ million for mission operations (Asker 1993). Using a $15 \mathrm{klbf}$ CIS/NTRE 
injection stage, $-508 \mathrm{~kg}$ of payload mass (both PFF/SC and more) can be launched on a single Titan IV (see Table 1) eliminating the need for two Centaur upper stages, four solid fuel kick motors and an additional Titan IV. The single mission cost savings of $\sim \$ 550$ million would also provide a significant down payment toward US/CIS NTRE development and ground test facility construction which are estimated to cost $\sim \$ 1.5$ billion.

Table 1 illustrates the mission performance benefits of using lighter weight, higher strength materials, such as graphite/epoxy $(\mathrm{Gr} / \mathrm{Ep})$ and aluminum-lithium $(\mathrm{Al} / \mathrm{Li})$ in place of traditional aluminum (Al) alloys, for fabrication of $\mathrm{LH}_{2}$ tank and stage structural components. Aluminum alloy 2219-T87 $\left(\mathrm{F}_{\mathrm{w}}=62 \mathrm{ksi}\right)$ is used extensively today in cryogenic tank construction. It has a relatively high strength-to-density ratio, good toughness and is weldable. It is also presently used in the $\mathrm{LOX}_{\mathrm{LH}}$ extemal tank of NASA's Space Shuttle. Aluminum-lithium alloy 2195 $\left(F_{\mathrm{m}}=90 \mathrm{ksi}\right)$ is a candidate $\mathrm{Al} / \mathrm{Li}$ alloy for cryogenic tank construction. It is a high strength, weldable alloy and has good fracture toughness. IM7/977-2 is a graphite/epoxy composite $\left(F_{w} \sim 91 \mathrm{ksi}\right)$ consisting of carbon fiber and thermoplastically toughened epoxy. The chemical composition and structure of the IM7/977-2 laminate make it cryogenically tough and should make it resistant to radiation damage. Composite $\mathrm{LH}_{2}$ tanks of graphite/epoxy have been developed and tested as part of the National AeroSpace Plane (NASP) program. The much lower density and increased strength of graphite/epoxy offers the potential for truly significant weight savings over $\mathrm{Al}$ and $\mathrm{Al} / \mathrm{Li} \mathrm{LH}_{2}$ tanks sized for the same conditions. This weight savings can be leveraged to carry either more payload or more propellant allowing higher energy, shorter transit time missions to Pluto as shown in Table 1. Tank wall thickness and weight estimates were calculated assuming a maximum internal pressure of $35 \mathrm{psi}(241.3 \mathrm{kPa})$ and included hydrostatic loads using a " $4-\mathrm{g}$ " launch load and a safety factor of 1.5 . A $2.5 \%$ ullage was also assumed.

Using 2219-T87 Al for the NTR injection stage tankage and structure, two PFF/SC plus support equipment $\left(\sim 508 \mathrm{~kg}\right.$ in all) can be launched in 2001 with a Pluto flyby occurring $\sim 9.15$ years later. The injection $C_{3}$ and $\Delta V$ requirements for this mission option are $\sim 215.56 \mathrm{~km} / \mathrm{s}^{2}$ and $\sim 11.55 \mathrm{~km} / \mathrm{s}$, respectively. Included in the $\Delta V$ estimate are gravity losses amounting to $-985 \mathrm{~m} / \mathrm{s}(-8.5 \%$ of the total $\Delta \mathrm{V})$ based on the conditions shown in Figure 1 . The total injection stage length is $\sim 19.7 \mathrm{~m}$ and includes the $13.5 \mathrm{~m}$ long $\mathrm{LH}_{2}$ tank and the $4.3 \mathrm{~m}$ long $15 \mathrm{klbf}$ CIS/NTRE. With $\sim 3.0 \mathrm{~m}$ required for the two PFF/SC and support equipment, the total vehicle length is $\sim 22.7 \mathrm{~m}$ which is within the $23.9 \mathrm{~m}$ limit of the extended $(86 \mathrm{ft} / 26.2 \mathrm{~m})$ Titan IV fairing. The NTR injection stage TPS also includes 1.5 inches of PVC closed cell foam (at 1.0 inch) and multilayer insulation (MLI at 0.5 inches) required for "ground hold" thermal protection of "wet-launched" $\mathrm{LH}_{2}$ tanks. The installed density of the TPS is $-1.625 \mathrm{~kg} / \mathrm{m}^{2}$ of $\mathrm{LH}_{2}$ tank surface area. The total mass of the "wet" injection stage (minus its $\sim 0.51 \mathrm{t}$ payload) is $\sim 19.49 \mathrm{t}$ and includes the $-5.21 \mathrm{t}$ "dry" injection stage (of which $2.56 \mathrm{t}$ is the NTRE) and $\sim 14.28 \mathrm{t}$ of $\mathrm{LH}_{2}$ propellant. A $15 \%$ contingency factor is also included in the weight estimates of both the engine and stage components.

TABLE 1. Pluto "Fast Flyby" (PFF) Mission Capability Using CIS/NTRE Injection Stage.

\begin{tabular}{|c|c|}
\hline $\begin{array}{l}\text { Tankage / Structural } \\
\text { Material }\end{array}$ & $\begin{array}{l}\text { Flight Time to Pluto (yrs.)/Injection } \mathrm{C}_{3}\left(\mathrm{~km}^{2} / \mathrm{s}^{2}\right) / \\
\mathrm{LH}_{2} \text { Tank Length }(\mathrm{m}) / \text { Total Vehicle Length }(\mathrm{m})\end{array}$ \\
\hline $\begin{array}{l}2219-\mathrm{T} 87 \mathrm{Al} \\
\left(\rho=2821 \mathrm{~kg} / \mathrm{m}^{3}\right)\end{array}$ & $9.15 / 215.56$ / 13.5 / 22.7 \\
\hline $\begin{array}{l}\mathrm{Al} / \mathrm{Li} \text { Alloy } 2195 \\
\left(p=2711 \mathrm{~kg} / \mathrm{m}^{3}\right)\end{array}$ & $8.30 / 233.21 / 13.8 / 23.0$ \\
\hline $\begin{array}{l}\text { IM7/977 - 2 Gr/Ep } \\
\left(p=1577 \mathrm{~kg} / \mathrm{m}^{3}\right)\end{array}$ & $6.50 / 297.90 / 14.7 / 23.9$ \\
\hline \multicolumn{2}{|l|}{ Assumptions: } \\
\hline \multicolumn{2}{|c|}{$\begin{array}{l}\text { Single Titan IV launch w } / 20 \mathrm{t} \text { to LEO }(100 \mathrm{n} . \mathrm{mi} . / 185 \mathrm{~km} \text { circular) } \\
\text { CIS/NTRE (Isp }=960 \mathrm{~s} @ 3025 \mathrm{~K}, \mathrm{~F}=15 \mathrm{klbf}, \mathrm{F} / \mathrm{W} \text { eng }=3.06, \mathrm{~F} / \mathrm{W}=0.34) \\
\text { Payload: } 508 \mathrm{~kg}(2-\mathrm{PFF} / \mathrm{SC} \text { w } / \mathrm{adaptors}+173 \mathrm{~kg} \text { for separation propulsion unit) } \\
\text { NTR stage TPS: } 1 \text { " PVC foam }+0.5^{\prime \prime} \mathrm{MLI} @ 1.625 \mathrm{~kg} / \mathrm{m}^{2} \\
\text { Tank geometry: } 4.6 \mathrm{~m} \text { dia. cylinder } \sqrt{2 / 2} \text { domes (includes } 2.5 \% \text { ullage) } \\
\text { Max. total vehicle length: } \sim 23.9 \mathrm{~m} \text { available } \mathrm{w} / 86^{\prime} \text { Titan IV fairing }\end{array}$} \\
\hline
\end{tabular}




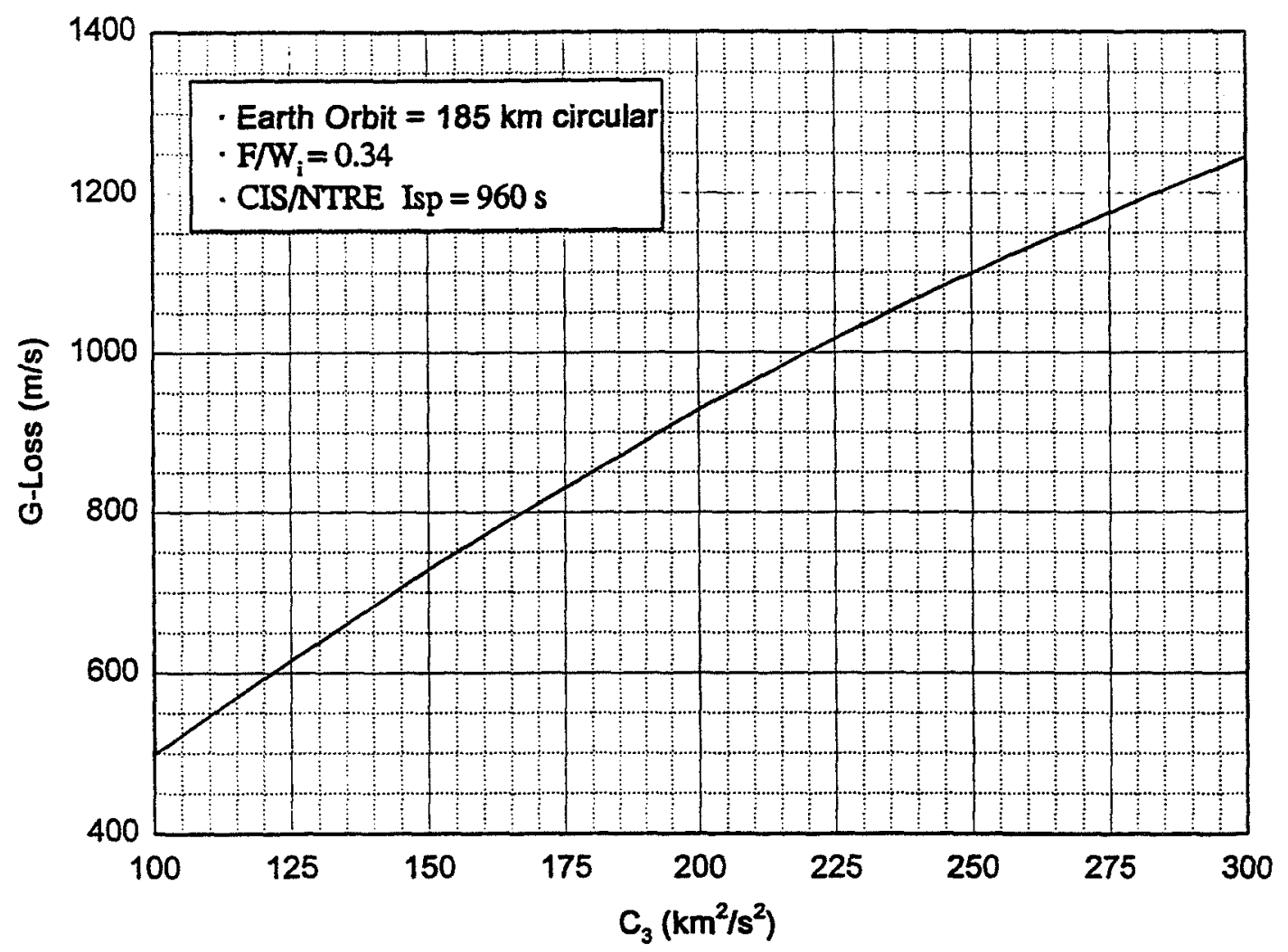

FIGURE 1. Gravity Loss Variation With Injection $C_{3}$ for Outer Planet Missions.

For the same IMLEO, payload and 2001 launch date, shorter Pluto transit times of 8.3 and 6.5 years are achievable using $\mathrm{Al} / \mathrm{Li}$ and $\mathrm{Gr} / \mathrm{Ep}$ tankage and structure, respectively. With $\mathrm{Al} / \mathrm{Li}$, the stage "dry" mass decreases to $4.89 \mathrm{t}$ while the $\mathrm{LH}_{2}$ propellant load increases to $-14.60 \mathrm{t}$. Similarly for $\mathrm{Gr} / \mathrm{Ep}$, the stage "dry" mass drops to $\sim 3.89 \mathrm{t}$ while the $\mathrm{LH}_{2}$ propellant load increases to $15.60 \mathrm{t}$. The stage mass fractions (minus the NTRE) for the Al, $\mathrm{Al} / \mathrm{Li}$ and $\mathrm{Gr} / \mathrm{Ep}$ systems are $-15.7,13.8$ and $7.9 \%$, respectively, and the corresponding engine burn times for the Pluto injection maneuver are $\sim 33.3,34.0$ and 36.2 minutes.

\section{Pluto Orbiter Mission}

While a flyby mission to Pluto will provide extremely valuable initial data, the small size of the PFF/SC and their short encounter time will impose significant limitations on their data gathering ability. Follow-up orbiter missions in the 2015 to 2020 timeframe with larger scientific payloads would provide a more comprehensive and detailed look at the Pluto/Charon system. The use of NTR propulsion for a Pluto orbiter mission has been examined previously by Zubrin and Sulmeisters (1992) assuming NERVA-derivative reactor (NDR) technology and by Venetoklis and Nelson (1993) with particle bed reactor (PBR) technology. Of the three NTR technologies, PBR, NDR, and now CIS, only the NDR and CIS concepts have undergone "proof-of-concept" validation and significant nuclear testing.

Pluto orbiter mission data using an expendable $15 \mathrm{kJbf}$ CIS/NTRE injection stage, a LOX/CH single Titan IV launch is summarized in Table 2 for different tank material and trip time combinations. With a December 2004 launch and a JGA maneuver at -15 Jupiter radii, spacecraft can be in orbit around Pluto in the 2017 to 2018 timeframe--13 to 14 years after launch. The injection $C_{3}$, total $\Delta V$ and gravity losses for the 13 year mission are $108.26 \mathrm{~km} 2 / \mathrm{s}^{2}, 7.902 \mathrm{~km} / \mathrm{s}$, and $0.538 \mathrm{~km} / \mathrm{s}(-6.8 \%$ of the total $\Delta \mathrm{V})$, respectively, and decrease to $106.4 \mathrm{~km} / \mathrm{s}^{2}, 7.831 \mathrm{~km} / \mathrm{s}$ and $0.529 \mathrm{~m} / \mathrm{s}$ for the 14 year mission. A "2 stage" LOX/CH 4 capture system ("core" stage plus drop tanks) with $10 \%$ stage mass fraction and Isp $=375$ seconds is used to place the scientific payioad into a $1650 \mathrm{~km}$ by $3000 \mathrm{~km}$ parking orbit around Pluto ( 1.1 by 2 Pluto radii). For 13 and 14 year transit times the arrival V-infinity values are 9.693 and $8.767 \mathrm{~km} / \mathrm{s}$, respectively, and the corresponding capture $\Delta V$ values are 8.870 and $7.951 \mathrm{~km} / \mathrm{s}$. An extra $200 \mathrm{~m} / \mathrm{s}$ is also added to the capture $\Delta V$ budget to accommodate midcourse corrections. 
TABLE 2. Pluto "Orbiter" Mission Capability Using CIS/NTRE Injection Stage.

\begin{tabular}{|l|c|c|}
\hline \multirow{2}{*}{$\begin{array}{c}\text { Tankage / Structural } \\
\text { Material }\end{array}$} & \multicolumn{2}{|c|}{$\begin{array}{c}\text { Pluto Orbiter / "Dry" Capture Stage / } \\
\text { LOX/CH } 4 \text { Propellant Mass (kg) }\end{array}$} \\
\cline { 2 - 3 } & 13 yrs. & 14 yrs. \\
\hline $\begin{array}{l}2219-\mathrm{T} 87 \mathrm{Al} \\
\left(\rho=2821 \mathrm{~kg} / \mathrm{m}^{3}\right)\end{array}$ & $167 / 351 / 3159$ & $244 / 350 / 3149$ \\
\hline $\begin{array}{l}\text { Al/ Ai Alloy } 2195 \\
\left(\rho=2711 \mathrm{~kg} / \mathrm{m}^{3}\right)\end{array}$ & $177 / 376 / 3384$ & $262 / 374 / 3367$ \\
\hline $\begin{array}{l}\text { IM7/977-2 Gr/Ep } \\
\left(\rho=1577 \mathrm{~kg} / \mathrm{m}^{3}\right)\end{array}$ & $212 / 450 / 4043$ & $312 / 446 / 4013$ \\
\hline
\end{tabular}

Assumptions:

1. Single Titan IV launch $w / 20 \mathrm{t}$ to LEO (100 n.mi./185 km circular)

2. CIS $/ \mathrm{NTRE}\left(\mathrm{Isp}=960 \mathrm{~s} @ 3025 \mathrm{~K}, \mathrm{~F}=15 \mathrm{kJbf}, \mathrm{F} / \mathrm{W}_{\mathrm{eng}}=3.06, \mathrm{~F} / \mathrm{W}_{\mathrm{i}}=0.34\right)$

3. NTR stage TPS: 1" PVC foam+0.5" MLI@ $1.625 \mathrm{~kg} / \mathrm{m}^{2}$

4. Tank dimensions: $4.6 \mathrm{~m}$ dia. $\times 11.1 \mathrm{~m}$ length (includes $2.5 \%$ ullage)

5. NTR stage length: $17.3 \mathrm{~m}$ w/6.6 m available for $\mathrm{LOX} / \mathrm{CH}_{4}$ capture stage

$(w / 10 \%$ stage mass fraction / Isp $=375 \mathrm{~s})+$ orbiter

An expendable NTR-powered injection stage with its Pluto orbiter spacecraft and $\mathrm{LOX} / \mathrm{CH}_{4}$ capture stage payload is depicted within the $26.2 \mathrm{~m}$ Titan IV fairing in Figure 2. The injection stage $\mathrm{LH}_{2}$ tank has a $4.6 \mathrm{~m}$ diameter, an $-11.1 \mathrm{~m}$ length with $\sqrt{2} / 2$ ellipsoidal domes and a propellant capacity of $-11.47 \mathrm{t}$ including a $1 \%$ reserve. It also includes: (1) a forward conical payload adaptor housing avionics, power and an attitude control system (ACS) for orientation control during the trans-Jupiter injection (TJn) burn; (2) forward and aft cylindrical band skirts; and (3) a rear conical adaptor or "thrust structure" for transferring in-space thrust loads from the $15 \mathrm{klbf}$ CIS/NTRE to the injection stage. The overall NTR stage length is $-17.3 \mathrm{~m}$. The LOX/CH, capture stage consists of an "in-line" 2-tank "core vehicle" and 6 "drop" tanks which are jettisoned half way through the Pluto capture burn. With an oxygen-to-methane propellant ratio of 3.6, three $\mathrm{CH}_{4}$ tanks and five LOX tanks are required each having a height equal to 3 tank radii. The overall length of the capture stage and orbiter spacecraft (assumed here to be $-1.2 \mathrm{~m}$ ) is $<4.8 \mathrm{~m}$ and can grow to as much as $6.6 \mathrm{~m}$ before reaching the $23.9 \mathrm{~m}$ maximum payload length limit.

Table 2 shows the distribution of total injected payload mass between the orbiter spacecraft, the "dry" capture stage and $\mathrm{LOX} / \mathrm{CH}_{4}$ propellant load for different Pluto trip times and tank material combinations. With an injection stage of 2219-T87 Al, $3.68 \mathrm{t}$ of payload can be sent to Pluto in 13 years using a JGA maneuver. The payload includes a $167 \mathrm{~kg}$ orbiter SC and a $3510 \mathrm{~kg}$ "wet" capture stage containing $3159 \mathrm{~kg}$ of LOX/CH4 propellant. Extending the transit time to 14 years increases the injected payload and reduces the capture $\Delta \mathrm{V}$ requirements resulting in an $46 \%$ increase in orbiter SC mass to $244 \mathrm{~kg}$. With a Gr/Ep injection stage, the orbiter mass can be increased an additional $27 \%$ to $212 \mathrm{~kg}$ and $312 \mathrm{~kg}$ for 13 and 14 year trip times, respectively. By contrast, a LOX/L $/ \mathrm{H}_{2}$-fueled Centaur upper stage can only inject enough mass to allow placement of $35 \mathrm{~kg}$ in orbit around Pluto. This mass is considered too small for a viable orbiter spacecraft. Table 2 demonstrates, rather convincingly, that a Pluto orbiter mission is enabled by NTR propulsion.

For the 13 year mission and Al tank option, the mass of the "wet" injection stage (minus payload) is $\sim 16.32 \mathrm{t}$ which includes the $-4.85 \mathrm{t}$ "dry" stage (with $2.56 \mathrm{t} \mathrm{NTRE)} \mathrm{and} \sim 11.47 \mathrm{t}$ of $\mathrm{LH}_{2}$ propellant. The same stage is used for the 14 year mission since it requires a comparable amount of propellant $(-11.41 \mathrm{t})$. For $\mathrm{Al} / \mathrm{Li}$, the stage "dry" mass is $\sim 4.59 \mathrm{t}$ with mass decreasing to $\sim 3.82 \mathrm{t}$ for the $\mathrm{Gr} / \mathrm{Ep}$ option. The corresponding stage mass fraction (minus the NTRE) for the $\mathrm{Al}, \mathrm{Al} / \mathrm{Li}$ and $\mathrm{Gr} / \mathrm{Ep}$ systems are $\sim 16.6,15.0$ and $9.9 \%$, respectively, and the engine burn time requirement for the injection maneuver is $\sim 26.7$ minutes. 

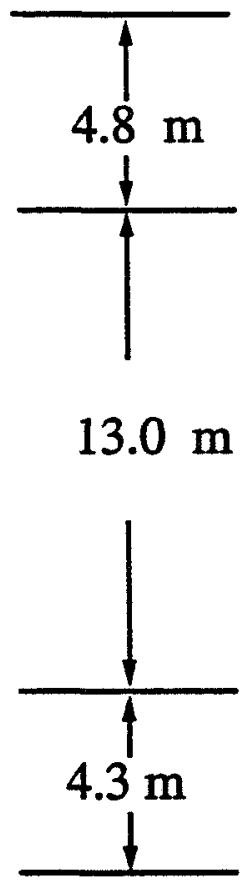

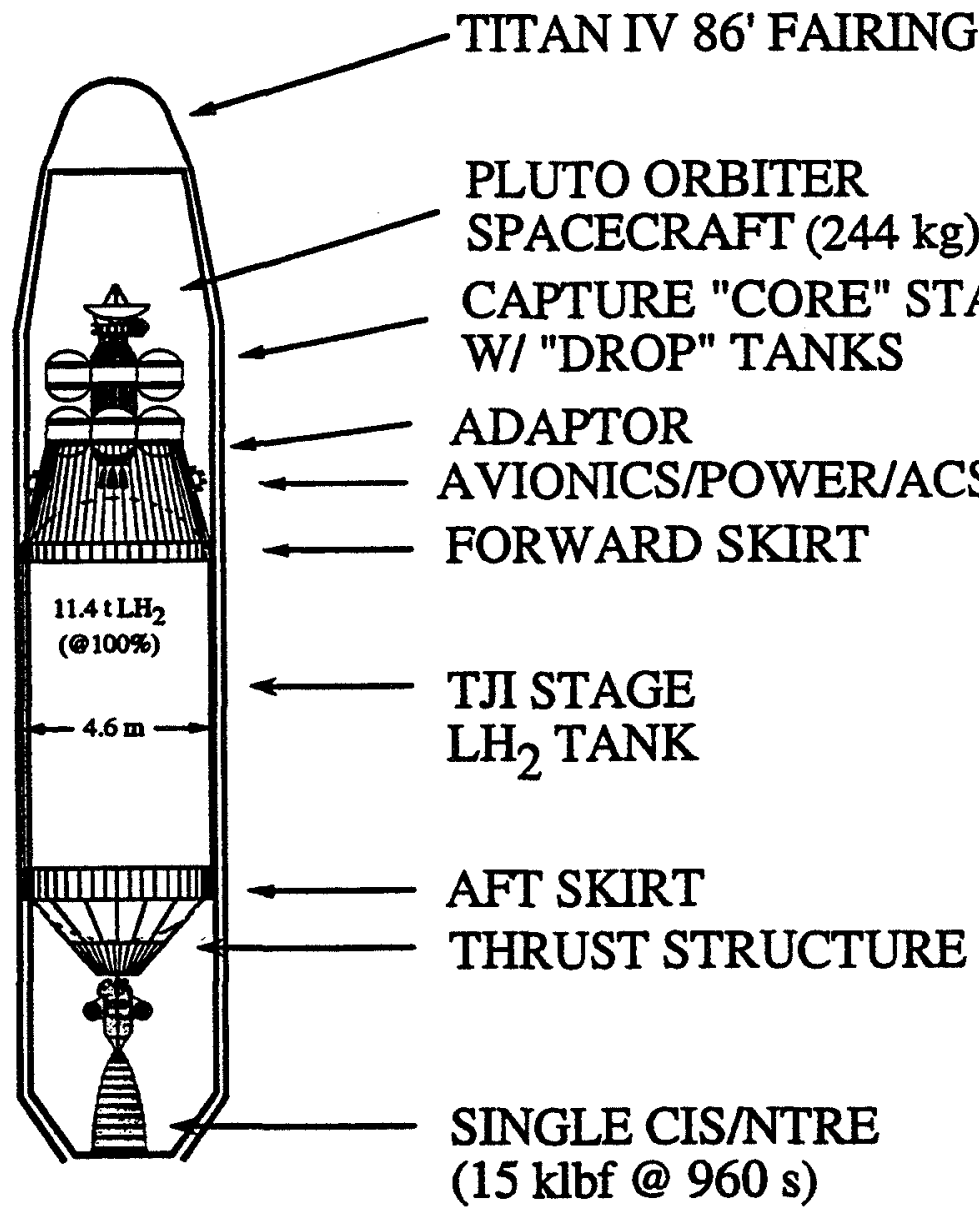

FIGURE 2. Packaging of NTR Injection Stage and Pluto Orbiter Payload in Titan IV Launch Vehicle.

\section{Saturn. Uranus and Neptune Orbiter Missions}

An NTR-powered injection stage can also enable high energy, "fast transit time" direct trajectory missions to the other planets of the outer solar system--Saturn, Uranus and Neptune. Direct orbiter missions (without gravity assists) are extremely difficult to accomplish with chemical propulsion because of the high injection $\Delta V$ requirements $(>9.5 \mathrm{~km} / \mathrm{s})$ and the limited amount of payload mass $(<100 \mathrm{~kg})$ which can be delivered to orbit. Direct trajectories also offer the mission designer continuous access to the outer planets with yearly launch opportunities, whereas Jupiter is only properly positioned to provide an outer planet trajectory assist for a certain period of time every 11.9 years.

Table 3 summarizes results for orbiter missions to Saturn, Uranus and Neptune using a common "fixed size" NTR injection stage, a storable propellant $\mathrm{N}_{2} \mathrm{O} / \mathrm{MMH}$ capture stage and a single Titan IV launch. The trip times examined here were reported previously by Zubrin and Sulmeisters (1992) assuming a circular orbit trajectory approximation, a constant injection $C_{3}$ of $\sim 152 \mathrm{~km}^{2} / \mathrm{s}^{2}$ and a $5 \%$ gravity loss. In this work, detailed trajectory analysis and "single burn" gravity loss estimates (shown in Figure 1) are included. For the same trip times, the injection $C_{3}$, total $\Delta V$ and gravity loss are: (1) $159.12 \mathrm{~km} / 2 / \mathrm{s}^{2}, 9.726 \mathrm{~km} / \mathrm{s}$ and $0.768 \mathrm{~km} / \mathrm{s}$, respectively, for Saturn; (2) $162.8 \mathrm{~km} 2 / \mathrm{s}^{2}, 9.850 \mathrm{~km} / \mathrm{s}$ and $0.783 \mathrm{~km} / \mathrm{s}$ for Uranus; and (3) $156.9 \mathrm{~km} 2 / \mathrm{s}^{2}, 9.649 \mathrm{~km} / \mathrm{s}$ and $0.758 \mathrm{~km} / \mathrm{s}$ for

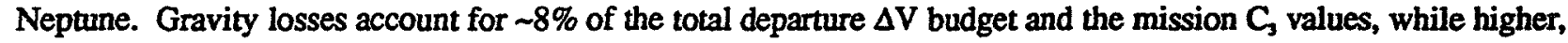
are approximately constant showing little variation with launch date. A single stage $\mathrm{N}_{2} \mathrm{O}_{4} / M M H$ capture system with $8 \%$ stage mass fraction and Isp $=330$ seconds is used to place the orbiter payloads into highly elliptical parking orbits $(\sim 2 \times 500$ planet radii). For arrival V-infinity values at Saturn, Uranus and Neptune of $14.61,11.54$ and 
TABLE 3. "Outer Planet" Orbiter Mission Capability Using CIS/NTRE Injection Stage.

\begin{tabular}{|c|c|c|c|}
\hline \multirow{2}{*}{$\begin{array}{c}\text { Tankage / Structural } \\
\text { Material }\end{array}$} & \multicolumn{3}{|c|}{ Planetary Orbiter / Dry" Capture Stage / $\mathrm{N}_{2} \mathrm{O}_{4}$ /MMH Mass (kg) } \\
\cline { 2 - 4 } & $\begin{array}{c}\text { Satum } \\
(2.3 \mathrm{yrs} .)\end{array}$ & $\begin{array}{c}\text { Uranus } \\
(6.6 \mathrm{yrs} .)\end{array}$ & $\begin{array}{c}\text { Neptune } \\
(12.6 \mathrm{yrs} .)\end{array}$ \\
\hline $\begin{array}{l}2219-\mathrm{T} 87 \mathrm{Al} \\
(\rho=2821 \mathrm{~kg} / \mathrm{m} 3)\end{array}$ & $341 / 126 / 1454$ & $334 / 119 / 1374$ & $779 / 96 / 1105$ \\
\hline $\begin{array}{l}\text { Al/Li Alloy } 2195 \\
(\rho=2711 \mathrm{~kg} / \mathrm{m} 3)\end{array}$ & $392 / 146 / 1674$ & $387 / 138 / 1593$ & $894 / 110 / 1267$ \\
\hline $\begin{array}{l}\text { IM7/977 - } 2 \mathrm{Gr} / \mathrm{Ep} \\
(\rho=1577 \mathrm{~kg} / \mathrm{m} 3)\end{array}$ & $543 / 201 / 2317$ & $542 / 194 / 2231$ & $1228 / 151 / 1741$ \\
\hline
\end{tabular}

Assumptions:

1. Single Titan IV Launch w/20 to LEO (100 n. mi./185 km circular)

2. CIS/NTRE (Isp $=960 \mathrm{~s} @ 3025 \mathrm{~K}, \mathrm{~F}=15 \mathrm{klbf}, \mathrm{F} / \mathrm{W}_{\mathrm{maz}}=3.06, \mathrm{~F} / \mathrm{W}_{\mathrm{i}}=0.34$ )

3. Direct missions to Satum, Uranus and Neptune w/injection $C_{3}=159,163$ and $157 \mathrm{~km}^{2} / \mathrm{s}^{2}$, respectively

4. NTR Stage TPS: 1" PVC foam + 0.5" MiI @ $1.625 \mathrm{~kg} / \mathrm{m}^{2}$

5. Tank dimensions: $4.6 \mathrm{~m}$ dia. $\times 12.5 \mathrm{~m}$ length (includes $2.5 \%$ ullage)

6. NTR stage length: $18.7 \mathrm{~m}$ w/5.2 $\mathrm{m}$ available for $\mathrm{N}_{2} \mathrm{O}, / \mathrm{MMH}$ capture stage

(w/8\% stage mass fraction $/ \mathrm{Isp}=330 \mathrm{~s}$ ) + orbiter

$8.85 \mathrm{~km} / \mathrm{s}$, respectively, the corresponding "ideal" capture $\Delta V$ values are $3.98,3.92$ and $2.22 \mathrm{~km} / \mathrm{s}$. These ideal values are increased by $10 \%$ to account for orbital capture gravity losses and an extra $200 \mathrm{~m} / \mathrm{s}$ is also added to the capture $\Delta \mathrm{V}$ budget to accommodate midcourse corrections.

Each mission class uses a "standardized" NTR injection stage which is sized by the Uranus orbiter mission. The $\mathrm{LH}_{2}$ tank length and propellant capacity are $\sim 12.5 \mathrm{~m}$ and $\sim 13.1 \mathrm{t}$, respectively, and the overall NTR stage length is $\sim 18.7 \mathrm{~m}$. Table 3 again shows the distribution of injected payload mass between the orbiter spacecraft, the "dry" capture stage and the $\mathrm{N}_{2} \mathrm{O} / \mathrm{MMH}$ propellant load for the different outer planet missions and assumed stage materials. For the 2.3 year mission to Saturn, orbiter SC mass increases from $341 \mathrm{~kg}$ to $543 \mathrm{~kg}$ in going from $\mathrm{Al}$ to $\mathrm{Gr} / \mathrm{Ep}$ stage construction with similar results obtained for the 6.6 year Uranus mission. The "standardized" NTR stage also allows orbiter SC masses ranging from $-779 \mathrm{~kg}$ (with $\mathrm{Al}$ ) to $\sim 1228 \mathrm{~kg}$ (with $\mathrm{Gr} / \mathrm{Ep}$ ) to be placed in Neptune orbit after a 12.6 year transit time. By comparison, the use of a $\mathrm{LOX}_{\mathrm{LH}} \mathrm{H}_{2}$ chemical injection system (with a $15 \%$ stage mass fraction and Isp $=460$ seconds) allows $<100 \mathrm{~kg}$ to be delivered to Saturn and Uranus and $<150 \mathrm{~kg}$ to Neptune for the same trip times.

The $\mathrm{N}_{2} \mathrm{O} / \mathrm{MMH}$ capture vehicle is a single stage four tank configuration with equal numbers of oxidizer and fuel tanks. The combined length of the capture stage and orbiter spacecraft is estimated to be between 3.2 and $3.5 \mathrm{~m}$ (assuming an $-1.2 \mathrm{~m}$ orbiter length) but can grow to as much as $5.2 \mathrm{~m}$. Including the $18.7 \mathrm{~m}$ NTR injection stage, the maximum total vehicle length is estimated to be $-22.2 \mathrm{~m}$. With a $\mathrm{LH}_{2}$ propellant load of $\sim 13 \mathrm{t}$ for each of the missions considered, the stage mass fractions (minus NTRE) for the $\mathrm{Al}, \mathrm{Al} / \mathrm{Li}$ and $\mathrm{Gr} / \mathrm{Ep}$ systems are $~ 16.2,14.6$ and $9.5 \%$, respectively, and are $\sim 0.4 \%$ less than that required for the Pluto orbiter mission. Finally, the engine bum time requirements for the trans-Saturn, -Uranus, and -Neptune injection maneuvers are relatively constant at $\sim 30.3$, 30.5 and 30.2 minutes, respectively.

\section{SUMMARY AND CONCLUSIONS}

This paper demonstrates quite dramatically that "exciting" orbiter missions to the outer planets can be "enabled" using NTR propulsion and further "enhanced" through the use of lightweight, high strength $\mathrm{Al} / \mathrm{Li}$ and $\mathrm{Gr} / \mathrm{Ep}$ materials for fabrication of $\mathrm{LH}_{2}$ tank and stage structural components. With an expendable upper stage powered by a $15 \mathrm{klbf}$ CIS/NTRE, over $500 \mathrm{~kg}$ of payload (the weight of two PFF/SC and more) can be delivered to Pluto in 6.5 
to 9.2 years using a single "Titan-IV-class" launch vehicle. A NTR-powered upper stage can also inject sufficient payload to enable a Pluto orbiter mission in the 2015 to 2020 timeframe, with spacecraft weight between -167 and $312 \mathrm{~kg}$. Fast transit time, direct missions to Saturn, Uranus and Neptune are also possible with orbiter payloads 340 to $820 \%$ larger than those achievable using a $\mathrm{LOX}_{\mathrm{L}} \mathrm{LH}_{2}$-fueled Centaur upper stage. The operational requirements imposed by the above missions on the CIS/NTRE's hydrogen exhaust temperature and burn duration have already been exceeded in reactor tests in the CIS, and provide confidence that a NTR-powered upper stage can be developed faster, cheaper and better through a joint US/CIS development effort. Beyond the "scientifically robust" Galileo and Cassini orbiter missions to Jupiter and Saturn, and a possible fast flyby mission to Pluto, there await orbiter missions to Uranus, Neptune and Pluto. With the development of NTR and Gr/Ep tank technologies, continuous access to the outer solar system will become a reality and the next "great age" of planetary exploration reminiscent of the Voyager program will begin.

\section{Acknowledgments}

This study was performed within the Advanced Space Analysis Office (ASAO) at NASA's Lewis Research Center in Cleveland, Ohio. The author gratefully acknowledges the programmatic support for this effort by ASAO and contributions made by Mr. Glen Horvat (LeRC/ASAO) and Mr. Stephen Hess (Analex/ASAO) in the areas of trajectory and gravity loss analysis. The author also wishes to thank Ms. Stacy Weinstein (JPL) for data on direct and gravity assisted trajectories to Pluto and the outer planets.

\section{References}

Asker, J. R. (1993) "Pluto Fast Flyby Slated for 2006," Aviation Week and Space Technology, 138 (7): 46-51, February 15, 1993.

Borowski, S. K. (1991) "The Rationale/Benefits of Nuclear Thermal Rocket Propulsion for NASA's Lunar Space Transportation System," AIAA-91-2052, presented at the 27th Joint Propulsion Conference, Sacramento, CA, 24-26 June 1991.

Borowski, S. K., J. S. Clark, R. J. Sefcik, R. R. Corban, and S. W. Alexander (1992) “An Accelerated Development, Reduced Cost Approach to Lunar/Mars Exploration Using a Modular NTR-Based Space Transportation System," IAF-92-0574, presented at the 43rd Congress of the International Astronautical Federation, Washington, D.C., August 28-September 5, 1992.

Borowski, S. K., R. R. Corban, M. L. McGuire, and E. G. Beke (1993) "Nuclear Thermal Rocket/Vehicle Design Options for Future NASA Missions to the Moon and Mars," AIAA-93-4170, presented at the AIAA Space Programs and Technologies Conference, Huntsville, AL, 21-23 September 1993.

Buden, D., L. R. Redd, T. S. Olson, and R. M. Zubrin (1993) "NTP Design Specifications for a Broad Range of Applications," AIAA-93-1947, presented at the 29th Joint Propulsion Conference, Monterey, CA, 28-30 June 1993.

Clark, J. S., M. C. Mcllwain, V. P. Smetanikov, E. K. D'yakov, and V. A. Pavshook (1993) “U.S./CIS Eye Joint Nuclear Rocket Venture," Aerospace America, 31 (7): 28-30, July 1993.

Culver, D. W., V. Kolganov, and R. Rochow (1994) "Low Thrust, Deep Throttling, US/CIS Integrated NTRE," in Proc. 11th Symposium on Space Nuclear Power and Propulsion, CONF-940101, M. S. El-Genk, ed., American Institute of Physics, New York, AIP Conference Proc. No. 301, 2: 637-651.

Koenig, D. R. (1986) Experience Gained from the Space Nuclear Rocket Program (Rover), LA-10062-H, Los Alamos National Laboratory, Los Alamos, NM. 
NASA (1989) Report of the 90-Day Study on Human Exploration of the Moon and Mars, National Aeronautics and Space Administration, Washington, D.C.

Synthesis Group (1991) America at the Threshold--America's Space Exploration Initiative, Report of the Synthesis Group, U.S. Government Printing Office, Washington, D.C.

Venetoklis, P., and C. Nelson (1993) "Pluto Exploration Strategies Enabled by SNTP Technology," AIAA-93-1951, presented at the 29th Joint Propulsion Conference, Monterey, CA, 28-30 June 1993.

Zubrin, R. M., and T. K. Sulmeisters (1992) "The Application of Nuclear Power and Propulsion for Space Exploration Missions," AIAA-92-3778, presented at the 28th Joint Propulsion Conference, Nashville, TN, 6-8 July 1992. 
Public reporting burden for this collection of intormation is estimated 10 average 1 hour per response, including the time for reviewing instructions, searching existing data sources, collection of information including suggestions for reducing this burden, to Washington Headquarters Services, Directorate for Information Operations and Reports, 1215 Jefferson Davis Highway, Suite 1204, Arlington, VA 22202-4302, and to the Office of Management and Budget, Paperwork Reduction Project (0704-01a8), Washington, DC 20503.

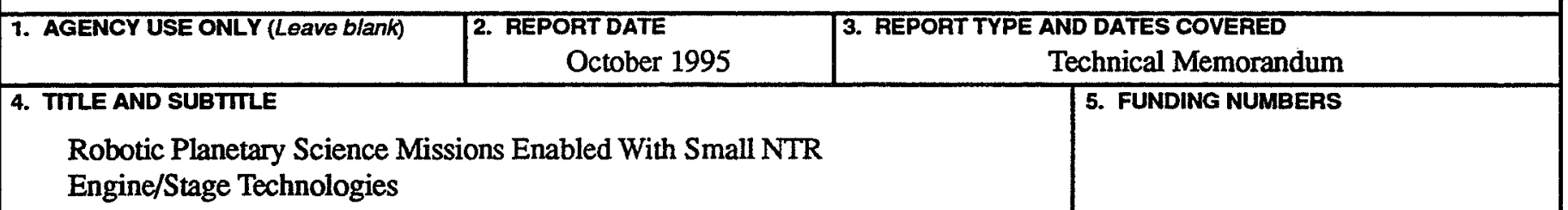

6. AUTHOR(S)

WU-242-10-01

Stanley K. Borowski

7. PERFORMING ORGANIZATION NAME(S) AND ADDRESS(ES)

8. PERFORMING ORGANIZATION REPORT NUMBER

National Aeronautics and Space Administration

Lewis Research Center

Cleveland, Ohio 44135-3191

E-9972

9. SPONSORING/MONITORING AGENCY NAME(S) AND ADDRESS(ES)

10. SPONSORING/MONITORING

AGENCY REPORT NUMBER

National Aeronautics and Space Administration

Washington, D.C. 20546-0001

NASA TM-107094

11. SUPPLEMENTARY NOTES

Prepared for the 12th Symposium on Space Nuclear Power and Propulsion cosponsored by BMDO, NASA, DOE, and USAF, Albuquerque, New Mexico, January 8-12, 1995. Responsible person, Stanley K. Borowski, organization code $6850,(216) 977-7091$.

12a. DISTRIBUTION/AVAILABILITY STATEMENT

12b. DISTRIBUTION CODE

Unclassified -Unlimited

Subject Categories 16 and 20

This publication is available from the NASA Center for Aerospace Information, (301) 621-0390.

13. ABSTRACT (Maximum 200 words)

The high specific impulse (Isp) and engine thrust-to-weight ratio of liquid hydrogen ( $\mathrm{LH}_{2}$ )-cooled nuclear thermal rocket (NTR) engines makes them ideal for upper stage applications to difficult robotic planetary science missions. A small 15 thousand pound force (klbf) NTR engine using a uranium-zirconium-niobium "ternary carbide" fuel (Isp $\sim 960$ seconds at $\sim 3025 \mathrm{~K}$ ) developed in the Commonwealth of Independent States (CIS) is examined and its use on an expendable injection stage is shown to provide major increases in payload delivered to the outer planets (Saturn, Uranus, Neptune and Pluto). Using a single "Titan IV-class" launch vehicle, with a lift capability to low Earth orbit (LEO) of $\sim 20$ metric tons ( $t$ ), an expendable NTR upper stage can inject two Pluto "Fast Flyby" spacecraft (PFF/SC) plus support equipment--combined mass of $-508 \mathrm{~kg}$-on high energy, "6.5-9.2 year" direct trajectory missions to Pluto. A conventional chemical propulsion mission would use a liquid oxygen (LOX)/ $\mathrm{LH}_{2}$ "Centaur" upper stage and two solid rocket "kick motors" to inject a single PFF/SC on the same Titan IV launch vehicle. For follow on Pluto missions, the NTR injection stage would utilize a Jupiter "gravity assist" (JGA) maneuver to launch a LOX/liquid methane $\left(\mathrm{CH}_{4}\right)$ capture stage (Isp 375 seconds) and a Pluto "orbiter" spacecraft weighing between $\sim 167-312 \mathrm{~kg}$. With chemical propulsion, a Pluto orbiter mission is not a viable option because of inadequate delivered mass. Using a "standardized" NTR injection stage and the same single Titan IV launch scenario, "direct flight" (no gravity assist) orbiter missions to Saturn, Uranus and Neptune are also enabled with transit times of 2.3, 6.6, and 12.6 years, respectively. Injected mass includes a storable, nitrogen tetroxide/monomethyl hydrazine $\left(\mathrm{N}_{2} \mathrm{O}_{4} / \mathrm{MMH}\right)$ capture stage (Isp $~ 330$ seconds) and orbiter payloads 340 to $820 \%$ larger than that achievable using a LOX/LH 2 -fueled injection stage. The paper discusses NTR technology and mission characteristics, shows NTR stage and payload accommodations within the $26.2 \mathrm{~m}$ long Titan IV payload fairing, and discusses NTR stage performance as a function of assumed cryogenic tank technology.

14. SUBJECT TERMS
Nuclear thermal rocket; NTR; Robotic science missions; Orbiter; Pluto fast flyby; Titan IV; Saturn; Uranus; Neptune

\begin{tabular}{|c|c|}
\hline $\begin{array}{c}\text { 17. SECURITY CLASSIFICATION } \\
\text { OF REPORT }\end{array}$ & $\begin{array}{c}\text { 18. SECURITY CLASSIFICATION } \\
\text { OF THIS PAGE } \\
\text { Unclassified }\end{array}$ \\
Unclassified
\end{tabular}
19. SECURITY CLASSIFICATION OF ABSTRACT Unclassified

\begin{tabular}{|c|}
\hline $\begin{array}{c}\text { 15. NUMBER OF PAGES } \\
11\end{array}$ \\
\hline $\begin{array}{r}\text { 16. PRICE CODE } \\
\mathrm{A03}\end{array}$ \\
\hline 20. LIMITATION OF ABSTRACT \\
\hline
\end{tabular}

Standard Form 298 (Rev. 2-89) Prescribed by ANSI SId. Z39-18 298-102 